\title{
Metabolomics Reveals Aryl Hydrocarbon Receptor Activation Induces Liver and Mammary Gland Metabolic Dysfunction in Lactating Mice
}

\author{
Kerry R. Belton, ${ }^{\dagger}$ Yuan Tian, ${ }^{\dagger \dagger}$ Limin Zhang, $^{\dagger, \ddagger}$ Mallappa Anitha, ${ }^{\dagger}$ Philip B. Smith, ${ }^{\S}$ Gary H. Perdew, ${ }^{\dagger}$
} and Andrew D. Patterson* ${ }^{\dagger}$ (i)

${ }^{\dagger}$ Department of Veterinary and Biomedical Sciences, Center for Molecular Toxicology and Carcinogenesis, The Pennsylvania State University, University Park, Pennsylvania 16802, United States

${ }^{\ddagger}$ CAS Key Laboratory of Magnetic Resonance in Biological Systems, State Key Laboratory of Magnetic Resonance and Atomic and Molecular Physics, National Centre for Magnetic Resonance in Wuhan, Wuhan Institute of Physics and Mathematics, University of Chinese Academy of Sciences, Wuhan 430071, P. R. China

${ }^{\S}$ Metabolomics Facility, The Pennsylvania State University, University Park, Pennsylvania 16802, United States

\section{Supporting Information}

ABSTRACT: The liver and the mammary gland have complementary metabolic roles during lactation. Substrates synthesized by the liver are released into the circulation and are taken up by the mammary gland for milk production. The aryl hydrocarbon receptor (AHR) has been identified as a lactation regulator in mice, and its activation has been associated with myriad morphological, molecular, and functional defects such as stunted gland development, decreased milk production, and changes in gene expression. In this study, we identified adverse metabolic changes in the lactation network (mammary, liver, and serum) associated with AHR activation using ${ }^{1} \mathrm{H}$ nuclear magnetic resonance (NMR)-based metabolomics. Pregnant mice expressing $A h r^{d}$ (low affinity) or

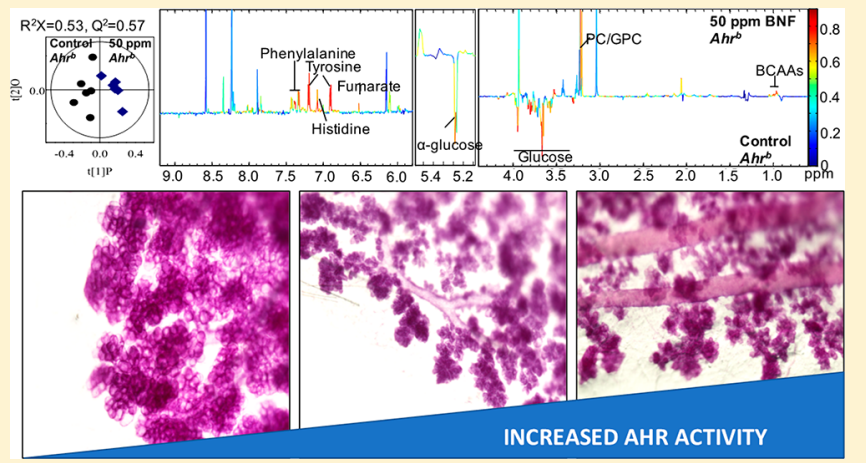
$A h r^{b}$ (high affinity) were fed diets containing beta naphthoflavone (BNF), a potent AHR agonist. Mammary, serum, and liver metabolomics analysis identified significant changes in lipid and TCA cycle intermediates in the $A h r^{b}$ mice. We observed decreased amino acid and glucose levels in the mammary gland extracts of $A h r^{b}$ mice fed BNF. The serum of BNF fed $A h r^{b}$ mice had significant changes in LDL/VLDL (increased) and HDL, PC, and GPC (decreased). Quantitative PCR analysis revealed $\sim 50 \%$ reduction in the expression of key lactogenesis mammary genes including whey acid protein, $\alpha$-lactalbumin, and $\beta$-casein. We also observed morphologic and developmental disruptions in the mammary gland that are consistent with previous reports. Our observations support that AHR activity contributes to metabolism regulation in the lactation network.

KEYWORDS: aryl hydrocarbon receptor, metabolomics, lactation

\section{INTRODUCTION}

Mammary gland differentiation during lactation is complex and is associated with extensive changes in its structure and function. ${ }^{1}$ During pregnancy, the gland becomes highly proliferative, initiating the development of epithelial ductal branching, elongation, and development of lobulo-alveolar structure. This differentiation process is hormone-dependent and its completion enables the synthesis of milk. The lactation process is regulated by endogenous hormones including prolactin, insulin, and corticosteroids. ${ }^{2}$

Strikingly, significant numbers of women annually are unable to initiate and nutritionally support their infants through breastfeeding or have difficulty doing so. ${ }^{3}$ Human epidemiological studies have demonstrated associations between environmental toxicants and defects in lactation and suggest exposure to endocrine disruptors (e.g., 2,3,7,8-tetrachlorodibenzodioxin, TCDD) during pregnancy have the potential to disrupt lactation. ${ }^{4-7}$ Several studies have shown that mammary gland differentiation defects are mediated through the aryl hydrocarbon receptor (AHR). ${ }^{3,6,8-10}$ However, the precise metabolic consequences of this dysregulation remain largely unclear and differences between mouse and human AHR in terms of their relative ligand affinities and selectivity further complicate understanding the role of the AHR in the mammary gland. ${ }^{11}$ Despite these complexities, the mouse has proven to be an invaluable tool for dissecting AHR signaling pathways in the mammary gland. $3,10,12-14$

Received: October 2, 2017

Published: March 9, 2018 
The AHR is a transcription factor expressed in various cell types and tissues, and studies have confirmed AHR maintains an important role in xenobiotic metabolism, immune homeostasis, and development. ${ }^{15}$ AHR plays a critical role in cell cycle control, regulation of apoptosis, and cell proliferation. ${ }^{16}$ The general role of the AHR in the mammary gland is not clearly understood, although mouse studies have revealed several critical physiological functions for this receptor related to mammary gland differentiation and lactation. For example, AHR protein was detected in the mammary glands during estrous-stimulated growth and branching of terminal end buds (TEBs). ${ }^{17}$ Comparative analysis of mammary gland development in $\mathrm{Ahr}^{-/-}$with $\mathrm{Ahr}{ }^{+/+}$littermates revealed a 50\% decline in the formation of TEBs in $\mathrm{Ahr}^{-/}$mice. These reports highlight the physiological role AHR likely plays in coordinating development, differentiation, cell growth, and signaling of hormones in mammary tissue.

The mouse $A h r^{b}$ (high affinity) or $A h r^{d}$ (low affinity) alleles express AHR that exhibits significant differences in TCDD responsiveness. The $A h r^{b}$ allele exhibits about 10-fold higher affinity for TCDD compared with $A h r$ expressed from the $A h r^{d} .^{18}$ Mice that express either the $A h r^{b}$ or $A h r^{d}$ alleles on the same genetic background provide an excellent model to further understand various mechanisms of AHR-mediated toxicity. ${ }^{19}$ In this study beta naphthoflavone (5,6-benzoflavone, BNF), a potent agonist of the $\mathrm{AHR}$, was given to pregnant mice via the diet to study its effects on lactation and metabolism. We report that dietary exposure to BNF significantly repressed mammary gland differentiation in the $A h r^{b}$ (high affinity) mice and induced metabolic abnormalities. Understanding mechanisms of AHR activation that lead to lactation dysregulation may suggest preventative strategies in humans.

\section{MATERIALS AND METHODS}

\section{Chemical Reagents}

5,6-Benzoflavone, carmine alum, paraformaldehyde, methyl salicylate, sodium chloride, $\mathrm{K}_{2} \mathrm{HPO}_{4}$, and $\mathrm{NaH}_{2} \mathrm{PO}_{4}$ (all analytical grade) were obtained from Sigma-Aldrich Chemical Co. Ltd. (St Louis, MO). Sodium 3-trimethylsilyl [2,2,3,3-d $\left.d_{4}\right]$ propionate (TSP- $\left.d_{4}\right)$ and $\mathrm{D}_{2} \mathrm{O}(99.9 \%)$ were purchased from Cambridge Isotope Laboratories (Miami, FL).

\section{Animals and Treatments}

C57Bl/6J mice expressing the $A h r^{b}$ or $A h r^{d}$ allele (6-8 weeks) were maintained at The Pennsylvania State University. The $A h r^{d}$ (low affinity) mice served as an additional control to determine if the effects of BNF were AHR-dependent. Female mice were housed in pairs with male mice and checked daily for the presence of vaginal plugs. Once vaginal plugs were observed in females, the males were removed, and the pregnant mice were housed in pairs for the remainder of the study. Mice were given diets containing 0.5 and $50 \mathrm{ppm} \mathrm{BNF}(0.5 \mathrm{mg}$ or $50 \mathrm{mg}$ per kilogram of AIN-76A diet, respectively) and control (Dyets, Inc., Bethlehem, PA) ad libitum and were maintained on a 12-h light cycle. BNF shows higher affinity for the $A h r^{b}$ allele. ${ }^{20}$ Doses were chosen based on previous reports; ${ }^{21,22}$ however, no studies to date have directly assessed the impact of BNF on lactation. Females were maintained on the diet treatment from conception until birth of their pups. Females were sacrificed 1 day after birth using $\mathrm{CO}_{2}$ asphyxiation. Mammary glands were removed, immediately used or frozen in liquid nitrogen, and stored at $-80{ }^{\circ} \mathrm{C}$. All animal treatments were conducted with the approval of the Institutional Animal Care and Use Committee of The Pennsylvania State University.

\section{Whole Mount Analysis}

The right and left inguinal mammary glands (\#5 and \#10) were carefully dissected 1 day after giving birth, spread on a glass slide, and fixed overnight in $4 \%$ paraformaldehyde solution. Samples were rehydrated (70\% ethanol for $30 \mathrm{~min}, 50 \%$ ethanol for $30 \mathrm{~min}, 30 \%$ ethanol for $20 \mathrm{~min}, 10 \%$ ethanol for 20 $\mathrm{min}$, and distilled water for $5 \mathrm{~min})$. Staining was performed overnight with carmine alum (0.2\% carmine dye and $0.5 \%$ aluminum potassium sulfate), followed by dehydration the following day (70\% ethanol for $30 \mathrm{~min}$, $90 \%$ ethanol for 30 $\mathrm{min}$, and $100 \%$ for $30 \mathrm{~min}$ ). Mammary glands were cleared with xylene overnight and maintained in methyl salicylate. Sections were examined on a Keyence BZ-9000 (Itasca, IL) and Olympus BX60 wide-field microscope (Olympus). Evaluation of mammary differentiation was performed without knowledge of treatment by three individuals. Images of the glands were given a differentiation score based on a four-point scale ( $1=$ poor development/differentiation to $4=$ excellent growth and development). The subjective scoring scales were based on the differentiation stage including degree of alveoli population, coverage of the adipose tissue, and density of alveoli present in the parenchymal tissue.

\section{HC11 Cell Culture and Induction with Lactogenic Hormones}

Mouse mammary epithelial cells (HC11) were used with the permission of Dr. Bernd Groner (Institute for Biomedical Research, Frankfurt, Germany). HC11 cells were maintained at $37{ }^{\circ} \mathrm{C}$ with $5 \% \mathrm{CO}_{2}$ in RPMI (HyClone, Logan, UT) medium containing $10 \%$ fetal bovine serum (HyClone, Logan, UT), ITS-X full form $(5 \mu \mathrm{g} / \mathrm{mL}$; Invitrogen, Carlsbad, CA), penicillin $(100 \mathrm{IU} / \mathrm{mL}) /$ streptomycin $(100 \mu \mathrm{g} / \mathrm{mL})$, glutamine (1X; Invitrogen, Carlsbad, CA), and murine epidermal growth factor (EGF; $10 \mathrm{ng} / \mathrm{mL} ; \mathrm{BD}$ Biosciences, San Jose, CA). For differentiation with lactogenic hormones $(\mathrm{LH})$, ovine prolactin $(5 \mu \mathrm{g} / \mathrm{mL}$; Sigma, St. Louis, MO) and dexamethasone (10 nM/ $\mathrm{mL}$; Sigma, St. Louis, MO) in EGF-free medium were used. For lactogenic differentiation, $1 \times 10^{6}$ cells per well were seeded onto 6-well tissue culture plates and grown to confluency. Twoday confluent cultures were washed twice with PBS and grown for 48 additional hours in culture media without EGF. EGF-free media was removed and replaced with media containing $\mathrm{LH}$ and grown for $24 \mathrm{~h}$. This media was removed after $24 \mathrm{~h}$. For treatment, LH media FBS were reduced to $2 \%$. Cells were treated with vehicle (0.1\% DMSO), 25, 50, and $100 \mu \mathrm{M}$ BNF based on previous reports. ${ }^{23}$ Throughout each BNF treatment assay, medium was replaced every $24 \mathrm{~h}$.

\section{Quantitative Real-Time PCR}

The left and right abdominal mammary glands (\#4 and \#9) were carefully dissected and flash frozen in liquid nitrogen 1 day after giving birth. RNA was extracted from frozen mammary tissue $(\sim 50 \mathrm{mg})$ or cells using TRIzol reagent (Invitrogen). All RNA samples were diluted to $1 \mu \mathrm{g} / \mu \mathrm{L}$ using nuclease free water. cDNA was synthesized in a $20 \mu \mathrm{L}$ reaction volume using $1.0 \mu \mathrm{g}$ of total RNA in $15 \mu \mathrm{L}$ of nuclease free water, $4 \mu \mathrm{L}$ qScript cDNA supermix (Quanta, Maryland). A total of $1 \mu \mathrm{L}$ of cDNA was added to $3.6 \mu \mathrm{L}$ of nuclease free water and $0.4 \mu \mathrm{L}$ of each forward and reverse primers were added to the solution ( $900 \mathrm{nM}$ forward, $900 \mathrm{nM}$ reverse). Gene-specific primers were used in each reaction, and all results 


\section{A $\quad A h r^{b}$, Control}

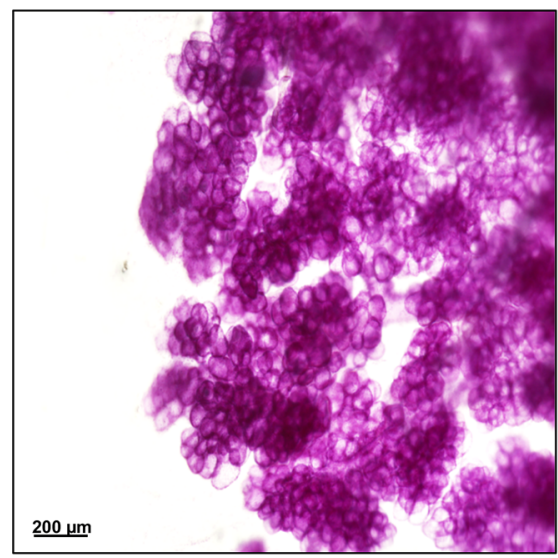

\section{D}

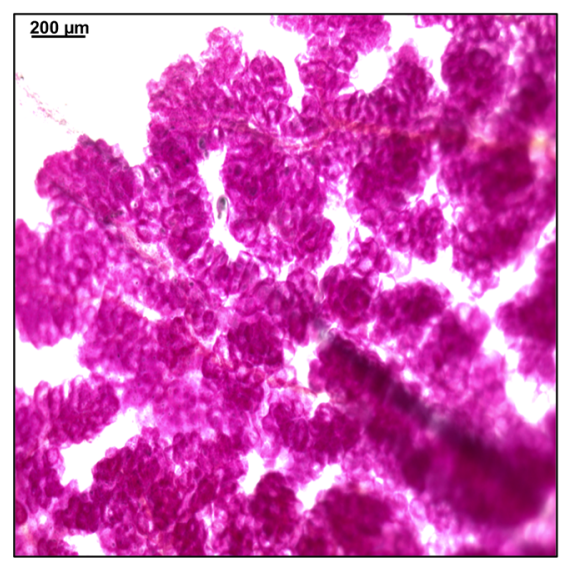

B

$A h r^{b}, 0.5$ ppm BNF

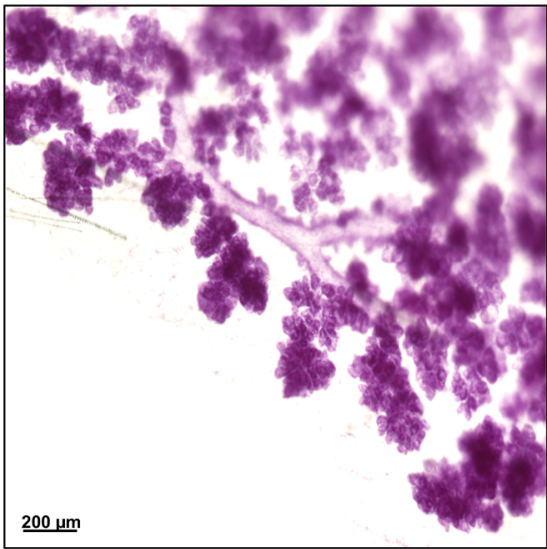

E

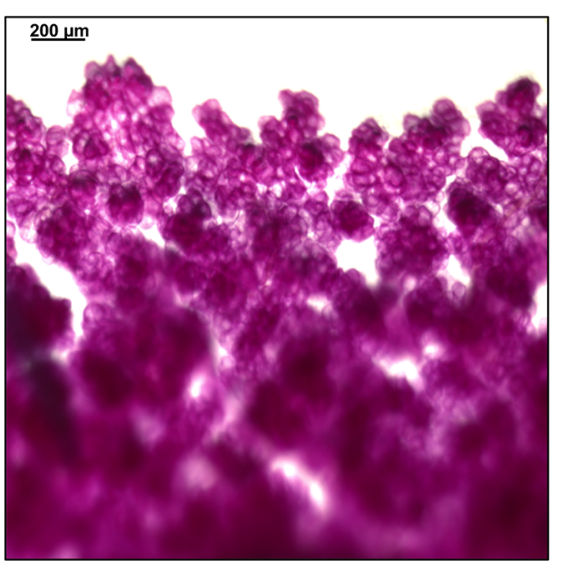

C $A h r^{b}, 50$ ppm BNF

Figure 1. BNF suppresses lactogenic mammary gland development. Female $A h r^{b}(n=6)$ mice were fed diets containing 0.5 or 50 ppm BNF ( 0.5 mg or $50 \mathrm{mg}$ per kilogram of base diet) and control ad libitum. Representative whole-mount images of the mammary glands from $A h r^{b}$ (A) control, (B) 0.5 ppm BNF-fed, and (C) 50 ppm BNF-fed mice are shown. BNF fails to suppress lactogenic mammary gland development in low affinity Ahr mice (D) control and (E) 50 ppm BNF-fed mice $(n=4)$. (F) An average differentiation score was determined in a blinded fashion. Results are shown as mean \pm SEM. All experimental data were analyzed using either one-way ANOVA (Ahr $\left.r^{b}\right)$ followed by Tukey's post analysis or unpaired $t$ test $\left(A h r^{d}\right)$. *P $\leq 0.05, * * P \leq 0.01$. Scale bar $=200 \mu \mathrm{m}$.

were normalized to $\beta$-actin. qPCR assays were carried out using SYBR Green PCR Master Mix (Applied Biosystems, California) on an ABI Prism 7900HT Fast Real-Time PCR sequence detection system (Applied Biosystems). The reactions were analyzed according to the $\Delta \Delta \mathrm{CT}$ method. qPCR conditions were 40 cycles at $95{ }^{\circ} \mathrm{C}$ for $20 \mathrm{~s} ; 95^{\circ} \mathrm{C}$ for $0.01 \mathrm{~s} ; 60^{\circ} \mathrm{C}$ for 30 $\mathrm{s} ; 95{ }^{\circ} \mathrm{C}$ for $15 \mathrm{~s} ; 60{ }^{\circ} \mathrm{C}$ for $15 \mathrm{~s}$; and $95{ }^{\circ} \mathrm{C}$ for $15 \mathrm{~s}$. Primers can be found in the Supporting Information (Table S1).

\section{${ }^{1} \mathrm{H}$ NMR-Based Metabolomics Experiments}

Serum, liver, and inguinal mammary gland sample preparation for NMR analyses were performed as previously described. ${ }^{24}$ Serum samples were prepared by mixing $200 \mu \mathrm{L}$ of serum with $400 \mu \mathrm{L}$ of saline solution containing $30 \% \mathrm{D}_{2} \mathrm{O} ; 550 \mu \mathrm{L}$ of samples was transferred into $5 \mathrm{~mm}$ NMR tubes after vortexing and centrifugation $\left(11180 \mathrm{~g}, 10 \mathrm{~min}, 4^{\circ} \mathrm{C}\right)$. Inguinal mammary glands (\#8 and \#10) and liver tissues ( $\sim 50 \mathrm{mg}$ ) were extracted three times with $600 \mu \mathrm{L}$ of a precooled methanol-water mixture $(2 / 1, v / v)$ using the Precellys tissue homogenizer (Bertin Technologies, Rockville, MD). After centrifugation at $11180 \mathrm{~g}$ for $10 \mathrm{~min}$ at $4{ }^{\circ} \mathrm{C}$, the combined supernatants were dried. Each of the aqueous extracts was separately reconstituted into $600 \mu \mathrm{L}$ of phosphate buffer $\left(\mathrm{K}_{2} \mathrm{HPO}_{4} / \mathrm{NaH}_{2} \mathrm{PO}_{4}, 0.1 \mathrm{M}\right.$,
$\left.\mathrm{pH} \quad 7.4,50 \% \quad \mathrm{v} / \mathrm{v} \quad \mathrm{D}_{2} \mathrm{O}\right)$ containing $0.005 \%$ sodium 3trimethylsilyl $\left[2,2,3,3-d_{4}\right]$ propionate $\left(\right.$ TSP- $\left.d_{4}\right)$ as chemical shift reference. Following centrifugation, $550 \mu \mathrm{L}$ of each extract was transferred into a $5 \mathrm{~mm}$ NMR tube for NMR analysis. For more detailed methods regarding ${ }^{1} \mathrm{H}$ NMR spectroscopy, see Supporting Information.

\section{Data Analysis}

All experimental data were analyzed using either one-way ANOVA followed by Tukey's post analysis ( $A h r^{b}$ group) or unpaired $t$-test $\left(A h r^{d}\right)$. Sample sizes are indicated in the figure legends. Graphical illustrations and statistical analysis were performed with GraphPad Prism version 6.0 (GraphPad, San Diego, CA). $P$-values $<0.05$ were considered statistically significant.

\section{RESULTS}

Effects of Dietary BNF on Mammary Gland Morphology $A h r^{b}$ and $A h r^{d}$ mice were treated with dietary BNF ( 0.5 or 50 ppm) throughout pregnancy. Food intake for 6-8 weeks old mice was estimated to be between 2.5 and $3.3 \mathrm{~g} /$ day. The dose of $\mathrm{BNF}$ provided to mice on the $0.5 \mathrm{ppm}$ diet was calculated to 

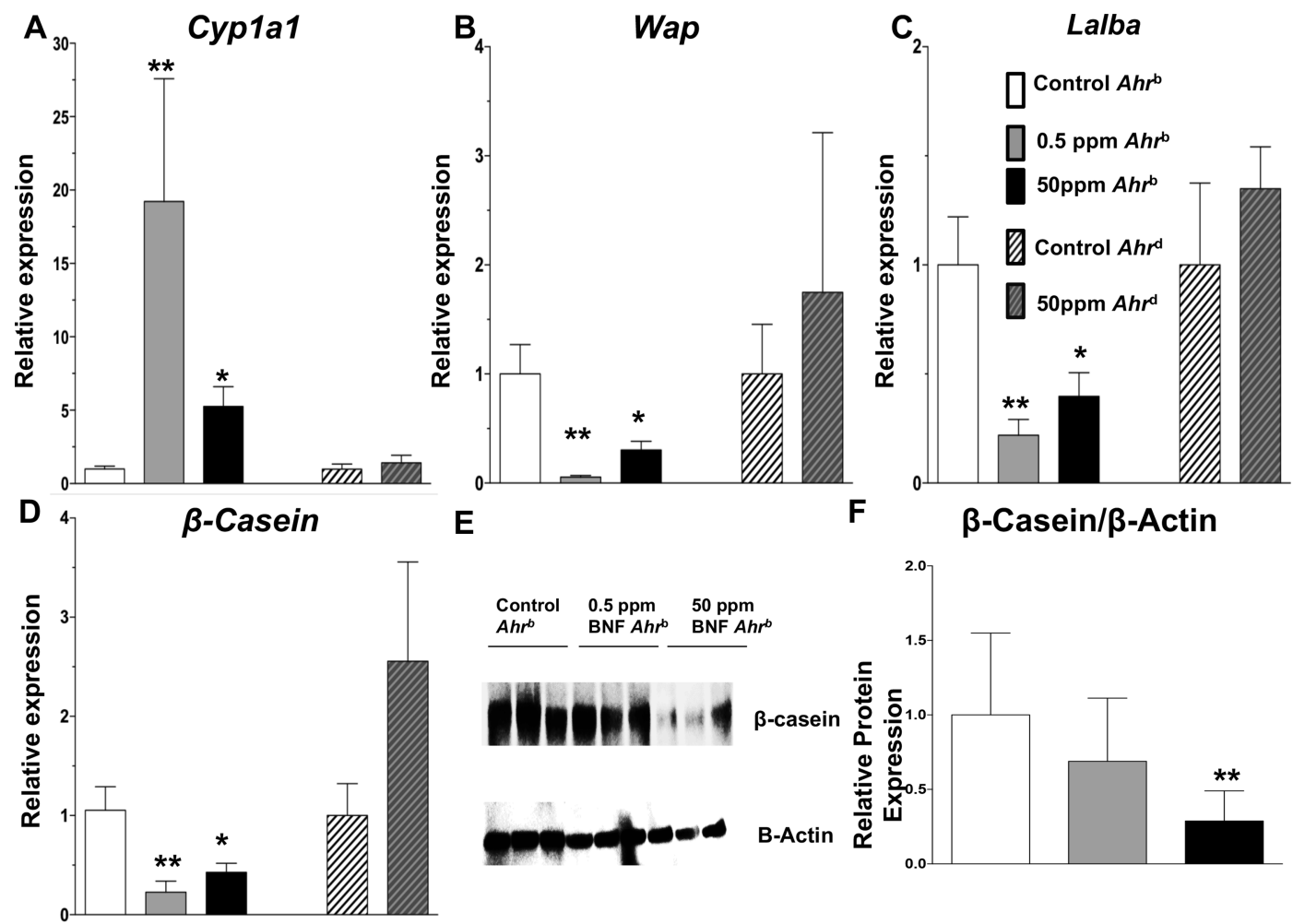

E

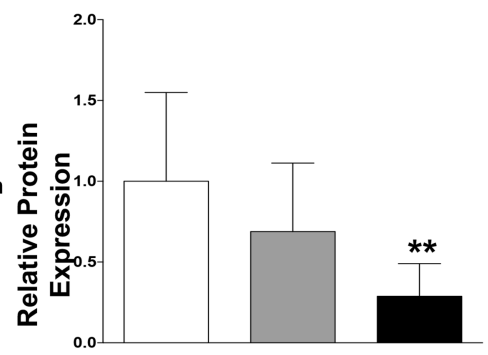

Figure 2. Dietary BNF suppresses lactogenic gene expression. Female $A h r^{b}(n=6)$ and $A h r^{d}(n=4)$ mice were sacrificed 1 day after giving birth to their pups. QPCR was used to measure lactogenic genes in both $A h r^{b}(n=6)$ and Ahr $r^{d}(n=4)$ mice including (A) Cyp1a1, (B) whey acid protein (Wap), (C) $\alpha$-lactalbumin (Lalba), and (D) beta-casein. Protein levels of $\beta$-casein (E) are suppressed following dietary BNF exposure. Densitometry reveals a significant decrease in $\beta$-casein (F). Results are shown as mean \pm SEM. All experimental data were analyzed using either one-way ANOVA $\left(A h r^{b}\right)$ followed by Tukey's post analysis or unpaired $t$-test $\left(A h r^{d}\right)$. *P $\leq 0.05, * * P \leq 0.01$.

be approximately $1-1.5 \mu \mathrm{g} / \mathrm{kg} /$ day while the dose of $\mathrm{BNF}$ provided to mice on the $50 \mathrm{ppm}$ BNF diet was calculated to be approximately $100-150 \mu \mathrm{g} / \mathrm{kg} /$ day. No differences in food intake or body weight were observed between the doses or genotypes (data not shown).

One day after parturition, mammary glands collected from control (no BNF) and low affinity $A h r^{d}$ mice treated with BNF were completely populated with alveoli, to such an extent that they covered the adipose tissue. As a result of the dense alveoli present, ductal structures were challenging to observe (Figure $1 A, D, E)$. The presence of milk could be noticed in the tissue during necropsy. In contrast, defects were visible in glands collected from high affinity $A h r^{b}$ mice treated with BNF. For instance, the adipose tissue was apparent, yet the parenchymal tissue contained fewer numbers of alveoli, and when present, they appeared unfilled and underdeveloped (Figure 1B,C). Based on blinded scoring, BNF exposure through the diet caused interruption of mammary gland development in $A h r^{b}$ mice treated with BNF (Figure 1F). BNF treated $A h r^{d}$ mice revealed mild but not statistically significant changes in morphology.

Effects of Dietary BNF on Overall Milk Secretion and Associated Milk Gene and Protein Expression

Analysis of the mammary gland tissue in $A h r^{b}$ mice revealed that dietary exposure induced a significant increase in the expression of Cyp1a1, in both BNF groups compared to control (Figure 2A). BNF altered the coordinated induction of milk protein gene expression (whey acid protein [Wap], $\beta$-casein, and $\alpha$-lactalbumin [Lalba]) by greater than $50 \%$ in both treatment groups compared to control (Figure 2B-D). BNF exposure
(50 ppm) in $A h r^{b}$ mice had significantly decreased $\beta$-casein protein expression (Figure 2E,F). Results from $A h r^{d}$ mice revealed no significant change in gene expression of these milk genes (Figure 2A-D).

BNF Inhibition of Milk Gene Expression in HC11 Mammary Epithelial Cells

In order to provide further validation of that the effects were due to BNF, HC11 mammary epithelial cell line cells were grown in the presence of BNF. HC11 cells can be induced to differentiate with lactogenic hormones $(\mathrm{LH})$ and produce milk proteins in culture. ${ }^{25,26}$ BNF significantly increased Cypla1 expression compared to control and LH-treated cells (Figure $3 \mathrm{~A})$. BNF significantly reduced $\beta$-casein gene expression relative to the LH-treated cells (Figure 3B). BNF considerably reduced Lalba and Wap expression relative to the LH-treated cells (Figure 3C,D).

${ }^{1} \mathrm{H}$ NMR-Based Metabolomics Reveal Negative Metabolic Effects of Dietary BNF on the Mammary Metabolome

We utilized ${ }^{1} \mathrm{H}$ NMR-based metabolomics to monitor metabolic changes and multivariate statistical analysis to evaluate the mammary, liver, and serum metabolome changes induced by BNF exposure. The model quality indicators $\mathrm{Q}^{2}$ were acceptable (Figure S1-3) and metabolite assignments consistent with previous reports (Figure S4, Table S2). ${ }^{24}$ Metabolomic analysis of the $A h r^{b}$ mammary gland revealed a decrease in glucose (Figure 4A) and increase in branched chain amino acids (BCAAs) and aromatic amino acids. $A h r^{b}$ BNF groups had an increase of the citric acid cycle (TCA) intermediate fumarate, suggesting decreased utilization and dysregulation of the TCA cycle and energy production (Figure 
A

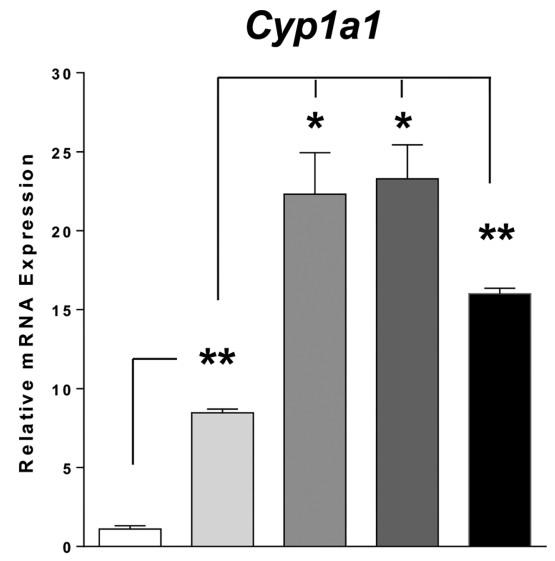

C

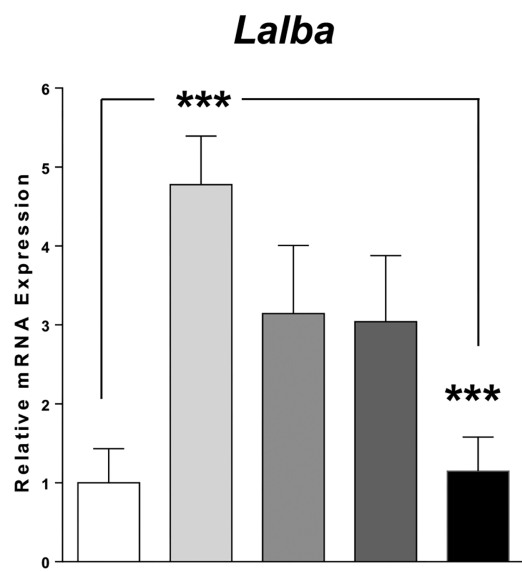

B

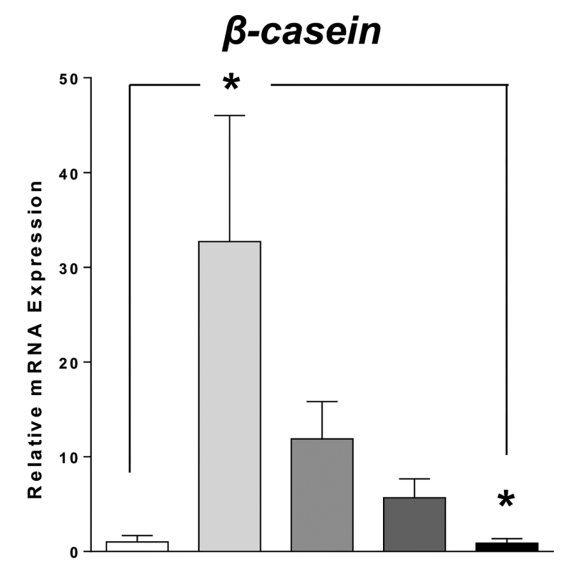

D

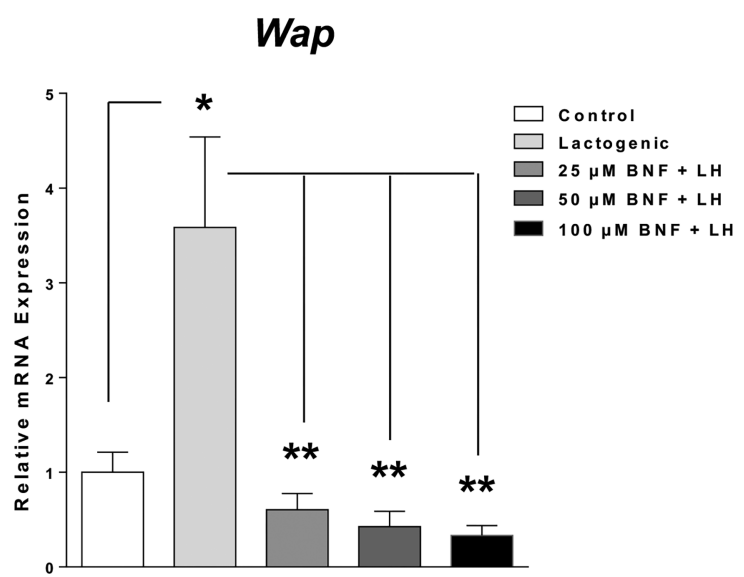

Figure 3. BNF treatment inhibits milk gene expression in HC11 mammary epithelial cells. mRNA expression measured by QPCR for HC11 cells. The cells were induced with lactogenic hormones (LH) to produce milk genes. Cells were then treated with DMSO (control) or BNF for $48 \mathrm{~h}$. mRNA levels for (A) Cyp1a1, (B) $\beta$-casein, (C) Lalba, and (D) Wap are normalized to $\beta$-actin. All experimental data were analyzed using one-way ANOVA followed by Tukey's post analysis compared to LH-treated cells. Results represent three wells per group and representative of two independent experiments. Data are shown as mean \pm SEM $* P \leq 0.05, * * P \leq 0.01, * * * P \leq 0.001$.

4A). Results from the $A h r^{d}$ mice revealed no changes in mammary gland metabolism (Figure 4D). These results suggest AHR may play a part in energy metabolism in the lactating mammary gland.

${ }^{1} \mathrm{H}$ NMR spectra of aqueous liver extracts and serum were obtained from control and those fed BNF. Spectra from liver extracts were predominantly amino acids (BCAAs, glutamine, glutamate, histidine, phenylalanine, and tyrosine), glucose, glycogen, choline-containing metabolites, and other metabolites such as lactate, fumarate, and succinate. Compared with controls, mice administered dietary BNF exhibited significantly reduced glucose in the liver (Figure 4B); however, no significant changes were observed in the $A h r^{d} 50 \mathrm{ppm}$ group (Figure 4E). Serum metabolomic analysis revealed that the 0.5 ppm BNF-fed mice caused a significant reduction in highdensity lipoprotein (HDL), phosphorylcholine (PC), and glycerylphosphorylcholine (GPC) levels compared to control (Figure 4C), while $0.5 \mathrm{ppm}$ fed mice had a significant increase very low-density lipoprotein (VLDL) and low-density lipoprotein (LDL; Figure 4C). The serum results from $A h r^{d} 50$ ppm group revealed no significant differences (Figure 4F).
Dietary BNF Alters Expression Profile of Mammary Gland Genes Associated Glucose and Amino Acid Metabolic Pathways

In order to monitor some of the transcriptional responses associated with BNF treatment that might further support the metabolomics data, we measured the expression of several key genes including glucose transporter 1 (Glut1) and solute carrier family 1 member 4 (Slc1a4) which are involved in glucose and amino acid transport, respectively. BNF exposure caused a significant decrease in Glut1 and Slcla4 in BNF fed Ahr mouse mammary gland tissue (Figure 5A,B). The results from the 50 ppm BNF fed $A h r^{d}$ group revealed no significant differences.

\section{DISCUSSION}

The mammary gland is one of the most active metabolic organs. Few studies have sought to characterize the metabolic perturbations associated with AHR mediated mammary gland dysregulation. The mammary gland, liver, and serum metabolome were monitored using ${ }^{1} \mathrm{H}$ NMR-based metabolomics. Our analyses revealed $A h r^{b}$ (high affinity) mice fed BNF had a significant decrease in amino acid and glucose utilization, which could be due to decreased glucose and amino acid transporter activity or to decreased release of glucose and amino acids to the serum from the liver. Studies have shown that glucose transport into the mammary epithelial cells and 

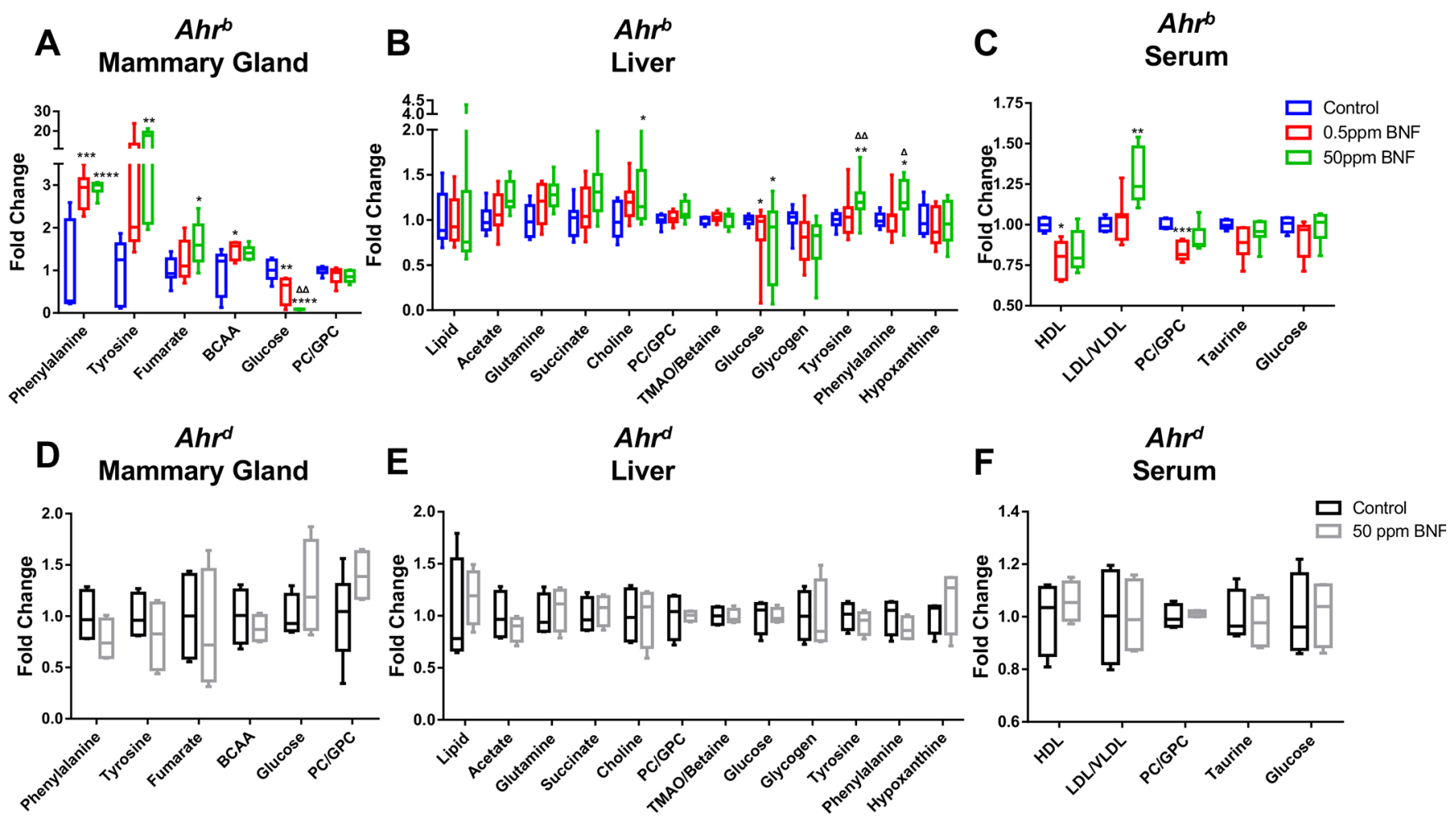

Figure 4. Effects of dietary BNF on lactating mammary gland, liver, and serum metabolic function. Relative content of metabolites in the mammary gland (A, D), liver (B, E), and serum (C, F) from $A h r^{b}$ and $A h r^{d}$ mice with or without dietary BNF $\left(0.5\right.$ and 50 ppm) were measured by ${ }^{1} \mathrm{H}$ NMR analysis. All experimental data were analyzed using either one-way ANOVA followed by Tukey's post analysis or unpaired $t$-test. Box and whisker plots represent the min to max ranges. ${ }^{*} P \leq 0.05$, ** $P \leq 0.01$, ***P $\leq 0.001$, ****P $\leq 0.0001$ compared to control; $\Delta P \leq 0.05, \Delta \Delta P \leq 0.01$ compared to $0.5 \mathrm{ppm}$ BNF.

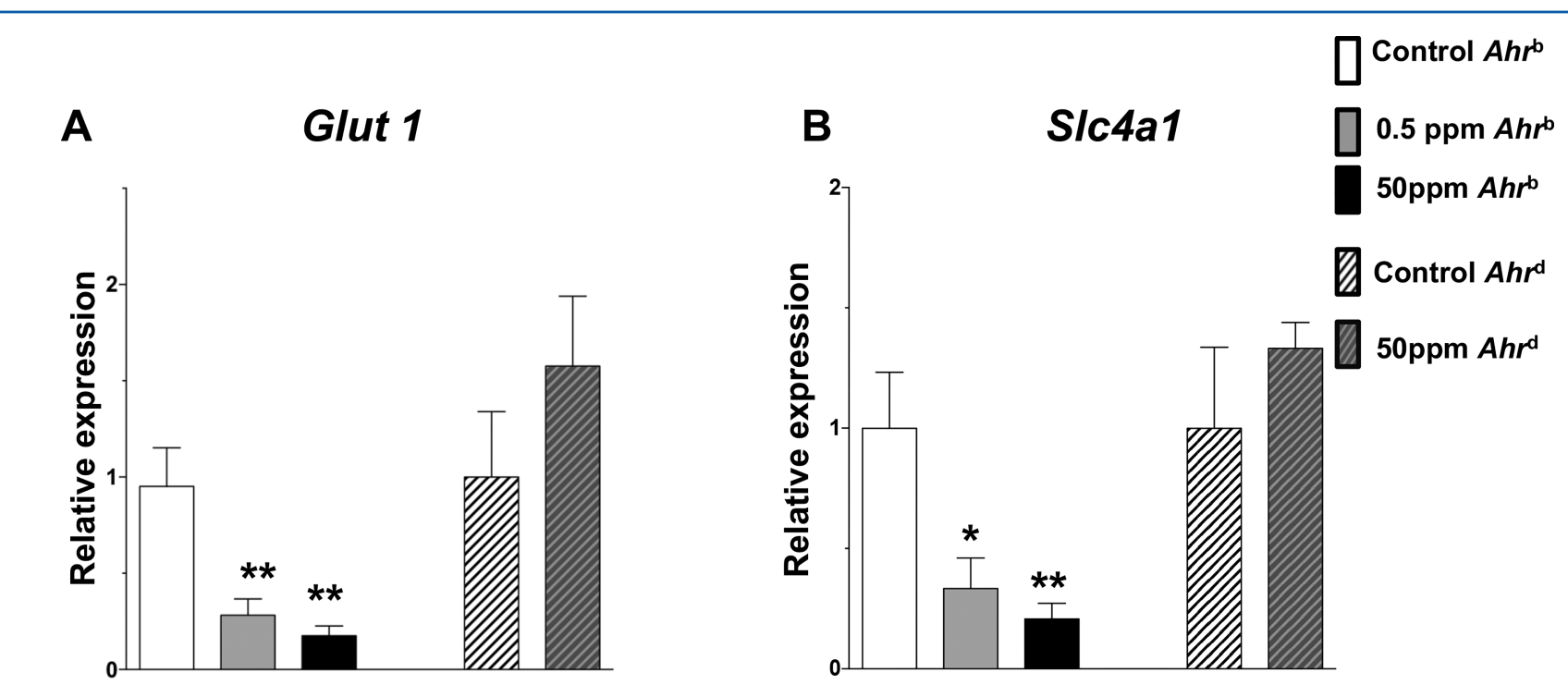

Figure 5. BNF suppresses glucose and amino acid transporters in mammary gland during lactation. Female $A h r^{b}(n=6)$ and $A h r^{d}(n=4)$ mice thoracic mammary glands were removed for RNA extraction. Gland mRNA expression was measured by QPCR to assess (A) Glut1 and (B) Slc1a4. All experimental data were analyzed using either one-way ANOVA followed by Tukey's post analysis or unpaired $t$-test. Results are shown as normalized mean \pm SEM $* P \leq 0.05, * * P \leq 0.01$.

their Golgi is facilitated by upregulation of Glut1 mRNA during lactation. ${ }^{27,28}$ Recent data also revealed that during lactation that mammary glands had increased cellular concentrations of amino acids (valine, leucine, isoleucine, alanine, and arginine) ${ }^{29}$ Other groups have suggested that amino acids are an important substrate for lipid synthesis at least in species that produce milk with a very high lipid content, such as the mouse. $^{28,29}$ Our results reveal AHR activation causes a significant decrease in Glut1 and Slc1a4 gene expression in the mammary glands of BNF exposed dams. In addition, other studies report TCDD significantly down regulated the expression levels of the Glut isoforms 1 and $3 .^{30}$ Further after $24 \mathrm{~h}$ TCDD treatment, GLUT1 was no longer localized in the plasma membrane of P19 cells. ${ }^{30,31}$ 
BNF-mediated AHR activation caused increase of the TCA intermediate fumarate, suggesting decreased utilization and dysregulation of the TCA cycle and energy production. A significant accumulation in aromatic amino acids (tyrosine, phenylalanine, and histidine) in mammary gland extracts suggested inhibited protein synthesis. Recent reports have shown aromatic amino acids (e.g., tryptophan) in culture medium are metabolized to ligands of $\mathrm{AHR}^{32}$ Our results suggest AHR may play a role in the metabolism of amino acids during lactation in the mammary gland. Results presented here revealed a significant accumulation of BCAAs, suggesting decreased utilization and possible metabolic dysregulation. However, it is likely this BCAAs accumulation stems from protein synthesis dysregulation considering that lactation increases the demand for protein synthesis. ${ }^{33}$ Interestingly, we also noted that in the $50 \mathrm{ppm} \mathrm{BNF-treated} A h r^{b}$, there was a significant increase in LDL/VLDL. Reports indicate that indeed LDL can activate $\mathrm{AHR},{ }^{34}$ that chronic, high dose exposure to the potent AHR ligand TCDD can impact VLDL secretion from the liver, ${ }^{35}$ and that ARH activation can exacerbate vascular inflammation in the ApoE-null mouse. ${ }^{36}$ These results suggest AHR may play a part in lipid and energy metabolism in the lactation network of the mouse and highlights that activation of AHR can lead to metabolic dysregulation in lactating mammary glands and liver.

Similar to other studies using the extensively investigated pollutant TCDD, our study suggests BNF interrupted the differentiation of the mammary gland and its associated milk production. ${ }^{10,12,37}$ However, we cannot exclude the possibility that a BNF metabolite could also promote these changes. Studies have shown that prenatal TCDD exposure can cause pups to gain significantly less weight. However, it is unclear whether this is due to physiological changes in the mammary of the dams or to the pups themselves. Future studies to understand the physiologic effects of BNF on the pups directly are warranted. Additionally, differences between mouse and human AHR activation should be assessed using humanized AHR mice.

In the current study, BNF impaired the production of milk protein genes $\beta$-casein, Wap, and Lalba in both in vitro and in vivo systems. ${ }^{13,14,38}$ Casein and whey protein, both important milk proteins, are molecular markers for functional differentiation in the mammary gland. ${ }^{27}$ Genes for these proteins are controlled by the lactogenic hormone prolactin, insulin, hydrocortisone, cell-cell interactions, and cell-substratum interactions. $^{28-30}$ Our data suggests that BNF impairs the production of milk via the disruption of milk protein genes and subsequently the reduction of their protein expression. Together these results further support the idea that activation of the AHR can lead to deleterious effects on mammary glands during lactation and strongly suggests more detailed examination of AHR-responsive genes in the mammary gland should be investigated.

\section{CONCLUSIONS}

Dietary exposure to the AHR ligand BNF induced mammary gland dysfunction in an Ahr-dependent manner. The data suggest, along with previous reports, that activation of the AHR can lead to alterations in several metabolic pathways, including perturbed TCA cycle and disrupted carbohydrate and amino acid metabolism. ${ }^{1} \mathrm{H}$ NMR analyses provided a new perspective for elucidating mechanisms of mammary gland toxicity; however, future studies will need to examine the metabolic response of specific cell types contained within the mammary gland. Further, characterization studies of AHR activators with more sensitive analytical methods could lead to biomarker identification of mammary toxicity during lactation. Our data has not completely pinpointed whether the effects seen are due to specific signaling events or the failure of the cells to differentiate. Overall, our findings highlight the role of the AHR in energy metabolism in the mammary gland during lactation.

\section{ASSOCIATED CONTENT}

\section{Supporting Information}

The Supporting Information is available free of charge on the ACS Publications website at DOI: 10.1021/acs.jproteome.7b00709.

Detailed methods of the NMR experiments. Figure S1: Loadings and scores plots of mammary metabolomics data from $A h r^{b}$ and $A h r^{d}$ mice. Figure S2: Loadings and scores plots of liver metabolomics data from $A h r^{b}$ and $A h r^{d}$ mice. Figure S3: Loadings and scores plots of serum metabolomics data from $A h r^{b}$ and $A h r^{d}$ mice. Figure S4: Typical $600 \mathrm{MHz}{ }^{1} \mathrm{H}$ NMR spectra of the liver (A), mammary (B), and serum samples (C) from $A h r^{b}$ control mice. Table S1: QPCR primer sequences. Table S2: NMR signal assignment table. (PDF)

\section{AUTHOR INFORMATION}

\section{Corresponding Author}

*Phone: 814-867-4565. E-mail: adp117@psu.edu. ORCID $\odot$

\section{Andrew D. Patterson: 0000-0003-2073-0070}

Notes

The authors declare no competing financial interest.

\section{ACKNOWLEDGMENTS}

This work was supported in part by the Training in Animal Models of Inflammation National Institute of Allergy and Infectious Disease award [T32AI074551], the Huck dissertation research award, the Bill and Melinda Gates Foundation, the National Institute of General Medical Sciences NIGMS [2R25GM078675-09A1], and National Institute of Environmental Health Sciences ES004869, ES022186, ES026684, and ES028244.

\section{REFERENCES}

(1) Fenton, S. E. Endocrine-Disrupting Compounds and Mammary Gland Development: Early Exposure and Later Life Consequences. Endocrinology 2006, 147 (6), s18-s24.

(2) Humphreys, R. C.; Lydon, J.; O’Malley, B. W.; Rosen, J. M. Mammary gland development is mediated by both stromal and epithelial progesterone receptors. Mol. Endocrinol. 1997, 11 (6), 801811.

(3) Lew, B. J.; Manickam, R.; Lawrence, B. P. Activation of the Aryl Hydrocarbon Receptor During Pregnancy in the Mouse Alters Mammary Development Through Direct Effects on Stromal and Epithelial Tissues. Biol. Reprod. 2011, 84, 1094-1102.

(4) Cupul-Uicab, L. A.; Gladen, B. C.; Hernández-Ávila, M.; Weber, J.; Longnecker, M. P. DDE, a degradation product of DDT, and duration of lactation in a highly exposed area of Mexico. Environ. Health Perspect. 2007, 116 (2), 179.

(5) Rudel, R. A.; Fenton, S. E.; Ackerman, J. M.; Euling, S. Y.; Makris, S. L. Environmental exposures and mammary gland development: 
state of the science, public health implications, and research recommendations. Environ. Health Perspect 2011, 119 (8), 1053-1061.

(6) Walsh, C. T.; Neville, M. C. Effects of xenobiotics on milk secretion and composition. J. Nutr. Biochem. 1994, 5 (9), 418-441.

(7) Swedenborg, E.; Rüegg, J.; Mäkelä, S.; Pongratz, I. Endocrine disruptive chemicals: mechanisms of action and involvement in metabolic disorders. J. Mol. Endocrinol. 2009, 43 (1), 1-10.

(8) Broquist, H. P. Lysine-pipecolic acid metabolic relationships in microbes and mammals. Annu. Rev. Nutr. 1991, 11 (1), 435-448.

(9) Mohammad, M. A.; Maningat, P.; Sunehag, A. L.; Haymond, M. W. Precursors of hexoneogenesis within the human mammary gland. American Journal of Physiology-Endocrinology and Metabolism 2015, 308 (8), E680-E687.

(10) Vorderstrasse, B. A.; Fenton, S. E.; Bohn, A. A.; Cundiff, J. A.; Lawrence, B. P. A novel effect of dioxin: exposure during pregnancy severely impairs mammary gland differentiation. Toxicol. Sci. 2004, 78 (2), 248-257.

(11) Flaveny, C. A.; Murray, I. A.; Perdew, G. H. Differential gene regulation by the human and mouse aryl hydrocarbon receptor. Toxicol. Sci. 2010, 114 (2), 217-25.

(12) Collins, L. L.; Lew, B. J.; Lawrence, B. P. TCDD exposure disrupts mammary epithelial cell differentiation and function. Reprod. Toxicol. 2009, 28 (1), 11-17.

(13) Lew, B. J.; Collins, L. L.; O’Reilly, M. A.; Lawrence, B. P. Activation of the aryl hydrocarbon receptor (AhR) during different critical windows in pregnancy alters mammary epithelial cell proliferation and differentiation. Toxicol. Sci. 2009, 111, 151.

(14) Lew, B. J.; Manickam, R.; Lawrence, B. P. Activation of the Aryl Hydrocarbon Receptor During Pregnancy in the Mouse Alters Mammary Development Through Direct Effects on Stromal and Epithelial Tissues. Biol. Reprod. 2011, 84 (6), 1094-1102.

(15) Kerdivel, G.; Habauzit, D.; Pakdel, F. Assessment and molecular actions of endocrine-disrupting chemicals that interfere with estrogen receptor pathways. Int. J. Endocrinol. 2013, 2013, 501851.

(16) Nebert, D. W.; Roe, A. L.; Dieter, M. Z.; Solis, W. A.; Yang, Y.; Dalton, T. P. Role of the aromatic hydrocarbon receptor and [Ah] gene battery in the oxidative stress response, cell cycle control, and apoptosis. Biochem. Pharmacol. 2000, 59 (1), 65-85.

(17) Hushka, L. J.; Williams, J. S.; Greenlee, W. F. Characterization of 2,3,7,8-Tetrachlorodibenzofuran-Dependent Suppression and $\mathrm{AH}$ Receptor Pathway Gene Expression in the Developing Mouse Mammary Gland. Toxicol. Appl. Pharmacol. 1998, 152 (1), 200-210.

(18) Poland, A.; Glover, E. Characterization and strain distribution pattern of the murine Ah receptor specified by the Ahd and Ahb-3 alleles. Mol. Pharmacol. 1990, 38 (3), 306-312.

(19) Ramadoss, P.; Perdew, G. H. Use of 2-azido-3-[125I] iodo-7, 8dibromodibenzo-p-dioxin as a probe to determine the relative ligand affinity of human versus mouse aryl hydrocarbon receptor in cultured cells. Molecular pharmacology 2004, 66 (1), 129-136.

(20) Maier, A.; Micka, J.; Miller, K.; Denko, T.; Chang, C. Y.; Nebert, D. W.; Puga, A. Aromatic hydrocarbon receptor polymorphism: development of new methods to correlate genotype with phenotype. Environ. Health Perspect 1998, 106 (7), 421-6.

(21) Torronen, R.; Karenlampi, S.; Pelkonen, K. Hepa-1 enzyme induction assay as an in vitro indicator of the CYP1A1-inducing potencies of laboratory rodent diets in vivo. Life Sci. 1994, 55 (24), $1945-54$.

(22) Lakshmi, V. M.; Hsu, F. F.; Zenser, T. V. Identification of new 2-amino-3-methylimidazo[4,5-f] quinoline urinary metabolites from beta-naphthoflavone-treated mice. Drug Metab. Dispos. 2009, 37 (8), 1690-7.

(23) Smith, K. J.; Murray, I. A.; Tanos, R.; Tellew, J.; Boitano, A. E.; Bisson, W. H.; Kolluri, S. K.; Cooke, M. P.; Perdew, G. H. Identification of a High-Affinity Ligand That Exhibits Complete Aryl Hydrocarbon Receptor Antagonism. J. Pharmacol. Exp. Ther. 2011, 338 (1), 318-327.

(24) Zhang, L.; Nichols, R. G.; Correll, J.; Murray, I. A.; Tanaka, N.; Smith, P. B.; Hubbard, T. D.; Sebastian, A.; Albert, I.; Hatzakis, E.; Gonzalez, F. J.; Perdew, G. H.; Patterson, A. D. Persistent Organic
Pollutants Modify Gut Microbiota-Host Metabolic Homeostasis in Mice Through Aryl Hydrocarbon Receptor Activation. Environ. Health Perspect 2015, 123 (7), 679-88.

(25) Ball, R.; Friis, R.; Schoenenberger, C.; Doppler, W.; Groner, B. Prolactin regulation of beta-casein gene expression and of a cytosolic $120-\mathrm{kd}$ protein in a cloned mouse mammary epithelial cell line. EMBO J. 1988, 7 (7), 2089.

(26) Danielson, K. G.; Oborn, C. J.; Durban, E. M.; Butel, J. S.; Medina, D. Epithelial mouse mammary cell line exhibiting normal morphogenesis in vivo and functional differentiation in vitro. Proc. Natl. Acad. Sci. U. S. A. 1984, 81 (12), 3756-3760.

(27) Macheda, M. L.; Williams, E. D.; Best, J. D.; Wlodek, M. E.; Rogers, S. Expression and localisation of GLUT1 and GLUT12 glucose transporters in the pregnant and lactating rat mammary gland. Cell Tissue Res. 2003, 311 (1), 91-97.

(28) Rudolph, M. C.; McManaman, J. L.; Phang, T.; Russell, T.; Kominsky, D. J.; Serkova, N. J.; Stein, T.; Anderson, S. M.; Neville, M. C. Metabolic regulation in the lactating mammary gland: a lipid synthesizing machine. Physiol. Genomics 2007, 28 (3), 323-36.

(29) Rudolph, M. C.; McManaman, J. L.; Phang, T.; Russell, T.; Kominsky, D. J.; Serkova, N. J.; Stein, T.; Anderson, S. M.; Neville, M. C. Metabolic regulation in the lactating mammary gland: a lipid synthesizing machine. Physiol. Genomics 2007, 28, 323.

(30) Tonack, S.; Kind, K.; Thompson, J. G.; Wobus, A. M.; Fischer, B.; Santos, A. N. Dioxin Affects Glucose Transport via the Arylhydrocarbon Receptor Signal Cascade in Pluripotent Embryonic Carcinoma Cells. Endocrinology 2007, 148 (12), 5902-5912.

(31) Liu, P.; Matsumura, F. Differential effects of 2, 3, 7, 8tetrachlorodibenzo-p-dioxin on the" adipose-type" and" brain-type" glucose transporters in mice. Mol. Pharmacol. 1995, 47 (1), 65-73.

(32) Veldhoen, M.; Hirota, K.; Christensen, J.; O'Garra, A.; Stockinger, B. Natural agonists for aryl hydrocarbon receptor in culture medium are essential for optimal differentiation of Th17 T cells. J. Exp. Med. 2009, 206 (1), 43-49.

(33) Tovar, A. R. Induction of Expression of Branched-Chain Aminotransferase and Alpha-Keto Acid Dehydrogenase in Rat Tissues During Lactation. Bioactive Components of Human Milk 2001, 501, 93.

(34) McMillan, B. J.; Bradfield, C. A. The aryl hydrocarbon receptor is activated by modified low-density lipoprotein. Proc. Natl. Acad. Sci. U. S. A. 2007, 104 (4), 1412-7.

(35) Nault, R; Fader, K. A.; Lydic, T. A.; Zacharewski, T. R. Lipidomic Evaluation of Aryl Hydrocarbon Receptor-Mediated Hepatic Steatosis in Male and Female Mice Elicited by 2,3,7,8Tetrachlorodibenzo-p-dioxin. Chem. Res. Toxicol. 2017, 30 (4), 10601075.

(36) Wu, D.; Nishimura, N.; Kuo, V.; Fiehn, O.; Shahbaz, S.; Van Winkle, L.; Matsumura, F.; Vogel, C. F. Activation of aryl hydrocarbon receptor induces vascular inflammation and promotes atherosclerosis in apolipoprotein E-/- mice. Arterioscler., Thromb., Vasc. Biol. 2011, 31 (6), 1260-7.

(37) Schlezinger, J.; Liu, D.; Farago, M. A role for the aryl hydrocarbon receptor in mammary gland tumorigenesis. Biol. Chem. 2006, 387 (9), 1175-87.

(38) Basham, K. J.; Leonard, C. J.; Kieffer, C.; Shelton, D. N.; McDowell, M. E.; Bhonde, V. R.; Looper, R. E.; Welm, B. E. Dioxin Exposure Blocks Lactation through a Direct Effect on Mammary Epithelial Cells Mediated by the Aryl Hydrocarbon Receptor Repressor. Toxicol. Sci. 2015, 143 (1), 36-45. 